\title{
CODE SINGLE POINT POSITIONING USING NOMINAL GNSS CONSTELLATIONS (FUTURE PERCEPTION)
}

\author{
A. M. A. Farah \\ Assistant Professor, Aswan-Faculty of Engineering, South Valley University, Egypt \\ Ashraf_farah@yahoo.com
}

\begin{abstract}
Global Navigation Satellite Systems (GNSS) have an endless number of applications in industry, science, military, transportation and recreation \& sports. Two systems are currently in operation namely GPS (the USA Global Positioning System) and GLONASS (the Russian GLObal NAvigation Satellite System), and a third is planned, the European satellite navigation system GALILEO. The potential performance improvements achievable through combining these systems could be significant and expectations are high. The need is inevitable to explore the future of positioning from different nominal constellations. In this research paper, Bernese 5.0 software could be modified to simulate and process GNSS observations from three different constellations (GPS, Glonass and Galileo) using different combinations. This study presents results of code single point positioning for five stations using the three constellations and different combinations.
\end{abstract}

Keywords: 1 . GNSS 2. Code 3. Point-Positioning 4.Bernese

\section{INTRODUCTION}

GNSS technology is a life need for present and future generations, with one reliable system (to some extent) "GPS", a system struggle to perform "Glonass" and a third system under developing "Galileo". The numerous GNSS dependent users are anxious to explore the future of GNSS with three systems will be in use. The user will have the privilege of using any of the three systems as well as any combinations of two systems or receiving signals from the three constellations at instant time.

Bernese 5.0 (Hugentobler et al., 2006) is highly acknowledged software which simulates and process GNSS observations from GPS and Glonass constellations. The software is delivered with the source code which gives the user the chance of modifying the software for further improvements. During this research, the author could modify the Bernese5.0 software to simulate and process different GNSS observations from GPS, Glonass and Galileo with different combinations of GPS/Glonass, GPS/Galileo, Galileo/Glonass and GPS/Glonass/Galileo. In this paper the code single point positioning results of processing different nominal constellations are presented. Table 1, shows parameters used for defining each nominal constellation. Firstly, a verification study is comparing the behaviour of the simulated GPS observations with real GPS observations will be presented to give the reader the trust in the following outputs for future combinations of constellations. 
Table 1. General Parameters for Defining Tested Nominal GNSS Constellations

\begin{tabular}{|l|c|c|c|}
\hline & GPS & Glonass & Galileo \\
\hline Total No. of satellites & 24 & 24 & 27 \\
\hline No. of planes & 6 & 3 & 3 \\
\hline Inclination (Deg.) & $55^{\circ}$ & $64.8^{\circ}$ & $56^{\circ}$ \\
\hline Semi-major axis (m) & 26561.75 & 25510.0 & 29600.318 \\
\hline Eccentricity (Deg.) & $0^{\circ}$ & $0^{\circ}$ & $0^{\circ}$ \\
\hline
\end{tabular}

\section{STUDY NETWORK}

The tested stations were five stations forming two main baselines one is east-west direction and the other baseline in north-south direction. Those five stations are a part from SAPOS network in Germany. The network is under the management of IPG (Institute of Physical Geodesy, Darmstadt University, Germany).

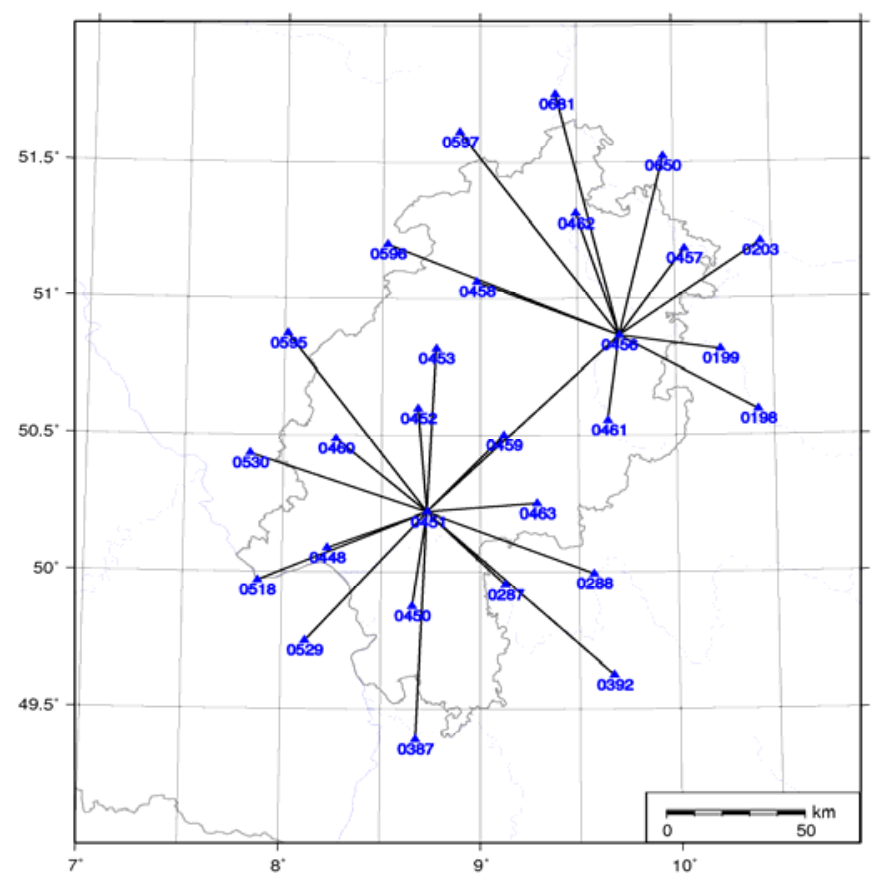

Fig. 1. SAPOS network.

\section{VERIFICATION STUDY}

The behaviour of real \& simulated GPS observations (from current GPS constellation) was tested to verify the study for future constellations. Both observations were processed using Code Single Point Positioning (CSPP). The A priori sigma code L1\&L2 values used for simulating the GPS simulated observations are shown in Table 2. Table 3 show RMS error difference for CSPP coordinates for tested five stations from Simulated \& real GPS observations. 
Table 2. A priori sigma code L1\& L2 values for stations used for simulating GPS observations using Bernese 5.0 software

\begin{tabular}{|l|c|}
\hline Constellation & Sigma code L1\&L2 (meter) \\
\hline GPS & 0.24 \\
\hline Glonass & 0.24 \\
\hline Galileo & 0.12 \\
\hline GPS/Glonass & 0.24 \\
\hline GPS/Galileo & 0.18 \\
\hline Galileo/Glonass & 0.18 \\
\hline GPS/Glonass/Galileo & 0.20 \\
\hline
\end{tabular}

Table 3. RMS error difference for CSPP coordinates for tested five stations from Simulated \& real GPS observations

\begin{tabular}{|l|c|c|c|c|c|}
\hline \multirow{2}{*}{ parameter } & \multicolumn{5}{|c|}{ Station ID } \\
\cline { 2 - 6 } & 0451 & 0518 & 0387 & 0453 & 0463 \\
\hline $\mathrm{X}(\mathrm{m})$ & 0 & 0 & 0.01 & 0.01 & 0 \\
\hline $\mathrm{Y}(\mathrm{m})$ & 0 & 0 & 0.01 & 0.01 & 0 \\
\hline $\mathrm{Z}(\mathrm{m})$ & 0 & 0 & 0.01 & 0.02 & 0 \\
\hline HEIGHT (m) & 0.01 & 0.01 & 0.02 & 0.02 & 0.01 \\
\hline $\begin{array}{l}\text { LATITUDE } \\
(\mathrm{sec})\end{array}$ & 0.0001 & 0.0001 & 0.0003 & 0.0003 & 0.0001 \\
\hline $\begin{array}{l}\text { LONGITUDE } \\
(\mathrm{sec})\end{array}$ & 0.0001 & 0.0001 & 0.0004 & 0.0004 & 0.0001 \\
\hline
\end{tabular}

The agreement is strongly proved for the code single point positioning (CSSP) results from real and simulated GPS observations. This is shown from the computed RMS values for both types of data from five stations. These results give the reader the confidence in this study's findings for future constellations

\section{CSPP USING DIFFERENT NOMINAL CONSTELLATIONS}

This study presents code single point positioning coordinates for tested five stations using different nominal constellations with different combinations (GPS, Glonass, Galileo, GPS/Glonass, GPS/Galileo, Galileo/Glonass and GPS/Glonass/Galileo).Tables 4 to 6 show the findings of this study which give more clear understanding of the quality of each CSPP results using different constellations.

Table 4. RMS error for CSPP coordinates for tested five stations from Simulated observations using nominal GPS\& Glonass and Galileo constellations

\begin{tabular}{|c|c|c|c|c|c|c|c|c|c|c|c|c|c|c|c|}
\hline \multirow{3}{*}{ parameter } & \multicolumn{15}{|c|}{ Station ID } \\
\hline & \multicolumn{3}{|c|}{0451} & \multicolumn{3}{|c|}{0518} & \multicolumn{3}{|c|}{0387} & \multicolumn{3}{|c|}{0453} & \multicolumn{3}{|c|}{0463} \\
\hline & GPS & GLO & GAL & GPS & GLO & GAL & GPS & GLO & GAL & GPS & GLO & GAL & GPS & GLO & GAL \\
\hline $\mathrm{X}(\mathrm{m})$ & 0.04 & 0.03 & 0.02 & 0.04 & 0.03 & 0.02 & 0.04 & 0.04 & 0.02 & 0.04 & 0.03 & 0.02 & 0.04 & 0.03 & 0.02 \\
\hline $\mathrm{Y}(\mathrm{m})$ & 0.02 & 0.02 & 0.01 & 0.02 & 0.02 & 0.01 & 0.02 & 0.02 & 0.01 & 0.02 & 0.02 & 0.01 & 0.02 & 0.02 & 0.01 \\
\hline $\mathrm{Z}(\mathrm{m})$ & 0.04 & 0.04 & 0.02 & 0.04 & 0.04 & 0.02 & 0.04 & 0.04 & 0.02 & 0.04 & 0.04 & 0.02 & 0.05 & 0.04 & 0.02 \\
\hline HT (m) & 0.05 & 0.05 & 0.02 & 0.05 & 0.05 & 0.02 & 0.05 & 0.05 & 0.02 & 0.05 & 0.05 & 0.02 & 0.05 & 0.05 & 0.02 \\
\hline $\begin{array}{l}\text { LAT } \\
(\mathrm{sec})\end{array}$ & 0.0009 & 0.0008 & 0.0003 & 0.0009 & 0.0008 & 0.0004 & 0.0009 & 0.0008 & 0.0003 & 0.0009 & 0.0008 & 0.0004 & 0.0009 & 0.0008 & 0.0003 \\
\hline $\begin{array}{l}\text { LONG } \\
(\mathrm{sec})\end{array}$ & 0.0011 & 0.0011 & 0.0004 & 0.0011 & 0.0011 & 0.0004 & 0.001 & 0.0011 & 0.0004 & 0.0011 & 0.0012 & 0.0004 & 0.0011 & 0.0011 & 0.0004 \\
\hline
\end{tabular}


Table 5. RMS error for CSPP coordinates for tested five stations from Simulated observations using different combinations of nominal constellations

\begin{tabular}{|c|c|c|c|c|c|c|c|c|c|c|c|c|c|c|c|}
\hline \multirow{3}{*}{ parameter } & \multicolumn{15}{|c|}{ Station ID } \\
\hline & \multicolumn{3}{|c|}{0451} & \multicolumn{3}{|c|}{0518} & \multicolumn{3}{|c|}{0387} & \multicolumn{3}{|c|}{0453} & \multicolumn{3}{|c|}{0463} \\
\hline & $\begin{array}{l}\text { GPS/ } \\
\text { GLO }\end{array}$ & $\begin{array}{l}\text { GPS/ } \\
\text { GAL }\end{array}$ & $\begin{array}{l}\text { GAL/ } \\
\text { GLO }\end{array}$ & $\begin{array}{l}\text { GPS/ } \\
\text { GLO }\end{array}$ & $\begin{array}{l}\text { GPS/ } \\
\text { GAL }\end{array}$ & $\begin{array}{l}\text { GAL/ } \\
\text { GLO }\end{array}$ & $\begin{array}{l}\text { GPS/ } \\
\text { GLO }\end{array}$ & $\begin{array}{l}\text { GPS/ } \\
\text { GAL }\end{array}$ & $\begin{array}{l}\text { GAL/ } \\
\text { GLO }\end{array}$ & $\begin{array}{l}\text { GPS/ } \\
\text { GLO }\end{array}$ & $\begin{array}{l}\text { GPS/ } \\
\text { GAL }\end{array}$ & $\begin{array}{l}\text { GAL/ } \\
\text { GLO }\end{array}$ & $\begin{array}{l}\text { GPS/ } \\
\text { GLO }\end{array}$ & $\begin{array}{l}\text { GPS/ } \\
\text { GAL }\end{array}$ & $\begin{array}{l}\text { GAL/ } \\
\text { GLO }\end{array}$ \\
\hline $\mathrm{X}(\mathrm{m})$ & 0.03 & 0.02 & 0.02 & 0.02 & 0.02 & 0.02 & 0.03 & 0.02 & 0.02 & 0.02 & 0.02 & 0.02 & 0.03 & 0.02 & 0.02 \\
\hline $\mathrm{Y}(\mathrm{m})$ & 0.02 & 0.01 & 0.01 & 0.02 & 0.01 & 0.01 & 0.02 & 0.01 & 0.01 & 0.02 & 0.01 & 0.01 & 0.02 & 0.01 & 0.01 \\
\hline $\mathrm{Z}(\mathrm{m})$ & 0.03 & 0.02 & 0.02 & 0.03 & 0.02 & 0.02 & 0.03 & 0.02 & 0.02 & 0.03 & 0.02 & 0.02 & 0.03 & 0.02 & 0.02 \\
\hline HT (m) & 0.04 & 0.02 & 0.02 & 0.04 & 0.02 & 0.02 & 0.04 & 0.02 & 0.02 & 0.04 & 0.02 & 0.02 & 0.04 & 0.02 & 0.02 \\
\hline $\begin{array}{l}\text { LAT } \\
(\mathrm{sec})\end{array}$ & 0.0006 & 0.0004 & 0.0004 & 0.0006 & 0.0004 & 0.0004 & 0.0006 & 0.0004 & 0.0004 & 0.0006 & 0.0004 & 0.0004 & 0.0006 & 0.0004 & 0.0004 \\
\hline $\begin{array}{l}\text { LONG } \\
(\mathrm{sec})\end{array}$ & 0.0008 & 0.0005 & 0.0005 & 0.0008 & 0.0005 & 0.0005 & 0.0008 & 0.0005 & 0.0005 & 0.0008 & 0.0005 & 0.0005 & 0.0008 & 0.0005 & 0.0005 \\
\hline
\end{tabular}

Table 6. RMS error difference for CSPP coordinates for tested five stations from Simulated observations using combined nominal constellation GPS/Glonass/Galileo

\begin{tabular}{|l|c|c|c|c|c|}
\hline \multirow{2}{*}{ parameter } & \multicolumn{5}{|c|}{ Station ID } \\
\cline { 2 - 6 } & 0451 & 0518 & 0387 & 0453 & 0463 \\
\hline $\mathrm{X}(\mathrm{m})$ & 0.02 & 0.02 & 0.02 & 0.02 & 0.02 \\
\hline $\mathrm{Y}(\mathrm{m})$ & 0.01 & 0.01 & 0.01 & 0.01 & 0.01 \\
\hline $\mathrm{Z}(\mathrm{m})$ & 0.02 & 0.02 & 0.02 & 0.02 & 0.02 \\
\hline HEIGHT $(\mathrm{m})$ & 0.02 & 0.02 & 0.02 & 0.02 & 0.02 \\
\hline LATITUDE $(\mathrm{sec})$ & 0.0004 & 0.0004 & 0.0004 & 0.0004 & 0.0004 \\
\hline LONGITUDE $(\mathrm{sec})$ & 0.0005 & 0.0005 & 0.0005 & 0.0005 & 0.0005 \\
\hline
\end{tabular}

\section{ANALYSIS \& DISCUSSIONS}

Table 3 shows the RMS difference of the CSPP coordinates using simulated GPS observations (using current constellation) and real GPS observations. The agreement is clear where the difference is $0.01 \mathrm{~m}$ for $\mathrm{X} \mathrm{Y}$, and $\mathrm{Z}$ coordinates for two stations and no difference at all for the rest three stations. For height latitude and longitude coordinates, the difference is no more than $0.02,0.0003$ and $0.0004 \mathrm{~m}$ respectively. This agreement gives the trust in other CSPP results for other tested scenarios.

Table 4 gives RMS error for CSPP coordinates for tested five stations from Simulated GPS\& Glonass and Galileo observations. It can be concluded that GPS and Glonass shows similar behaviour however Galileo gives better results with less RMS errors. The improvement in general is about 0.01 to $0.02 \mathrm{~m}$ for $\mathrm{X}, \mathrm{Y}$ and $\mathrm{Z}$ coordinates while it is about $0.03,0.0005$ and $0.0007 \mathrm{~m}$ for height, Latitude and Longitude coordinates.

Table 5 gives RMS error for CSPP coordinates for tested five stations from simulated observations using different combinations of constellations. It can be concluded that Galileo/GPS and Galileo/Glonass combinations shows similar behaviour which is better than GPS/Glonass combination behaviour. The improvement in general is about $0.01 \mathrm{~m}$ for $\mathrm{X}, \mathrm{Y}$ and $\mathrm{Z}$ coordinates while it is about $0.02,0.0002$ and $0.0003 \mathrm{~m}$ for height, Latitude and Longitude coordinates.

Table 6 gives RMS error difference for CSPP coordinates for tested five stations from Simulated observations using combined constellation GPS/Glonass/Galileo. It can be concluded that GNSS constellations combined from GPS, Glonass and Galileo offers similar behaviour to the behaviour of Galileo/GPS and Galileo/Glonass combinations which is better that GPS/Glonass combined constellation as stated before. 
Galileo gives better CSPP coordinates due to better geometry, more number of visible satellite and better ranging accuracy (A priori sigma code L1\&L2). Galileo has better ranging accuracy over GPS because of chip rate relations outline in Table 7.

Table 7. Chip rate relation between GPS signals and GALILEO signals (Farah, 2004)

\begin{tabular}{|l|c|}
\hline Signal & $\begin{array}{c}\text { Chip Rate } \\
\text { (Mcps) }\end{array}$ \\
\hline GPS-C/A CODE & 1.023 \\
\hline Galileo E2L1E1 & 2.046 \\
\hline Galileo E5AB & 10.000 \\
\hline Galileo E6 & 5.115 \\
\hline
\end{tabular}

\section{CONCLUSIONS}

Galileo constellation will provide better CSPP accuracy and hence better quality precise point positioning due to better geometry, more number of visible satellites and better ranging accuracy over GPS and Glonass. Combining Galileo constellations with GPS or Glonass will yield better behaviour over other combinations (GPS/Glonass). Modified Bernese software resulting from this research will give the ability of testing behaviour of different constellations present and future with different combinations for double-difference carrier phase solutions.

\section{ACKNOWLEDGMENT}

This research was conducted by the author during his three-month visit to the Institute of Physical Geodesy (IPG), Darmstadt University, Germany (November 06 to February 07). This visit was financed by the Egyptian government according to Arab Republic of Egypt Ministry of Higher Education and State for Scientific Research (MHESR) Partnership and Ownership Agreement initiatives. The author is grateful for the sincere help from Prof. M. Becker, Dean of the IPG and staff members of The IPG.

\section{REFERENCES}

Farah, A. (2004). GPS/GALILEO Simulation for Reduced Dynamic LEO satellite Orbit Determination. Ph.D. Thesis. Nottingham University. UK.

Urs Hugentobler, Rolf Dach, Pierre Fridez, and Michael Meindl (2006). Bernese GPS software version 5.0 Draft. Bern University, Switzerland

Received: 2008-01-22,

Reviewed: 2008-04-07, by S. Oszczak,

Accepted: 2008-04-08. 